\title{
PORTUGAL PENINSULAR E OS DESAFIOS REGIONAIS
}

\author{
SÉrgio Claudino ${ }^{1}$
}

\begin{abstract}
Resumo - Num continente sem rupturas físicas marcantes e assinalável unidade humana, as delimitações regionais portuguesas, surgidas na Idade Média, têm um carácter marcadamente corográfico. Nas suas designações, as comarcas, depois províncias, reflectem mais o olhar de quem vê o país a partir do seu centro político do que identidades assumidas pelas populações. No século XIX, sucumbem rapidamente aos distritos, construídos sobre municípios que os liberais reformam e viabilizam. Estimuladas pelo sempre decisivo poder central, as recentes tentativas de reconstrução do mapa regional, em renovada corografia, reflectem a necessidade de valorizar a escala supra-concelhia, num processo de associativismo municipal que se tenderá a aprofundar e em cujo desenvolvimento reconhecemos novas leituras da geografia regional.
\end{abstract}

Palavras-chave: Província, região, corografia, reforma, NUTS, município, associativismo.

\begin{abstract}
Mainland Portugal and Regional challenges. In a land noteworthy human unity and absent of marked physical disruption, the Portuguese regional delimitations that came about during the Middle Ages are clearly chorographic in nature. In terms of its designations, jurisdictions, and then provinces, more keenly reflect a political vision of the country than they do the way in which the people themselves identify with these places. In the $19^{\text {th }}$ century, they rapidly yielded to districts, built upon municipalities that liberals reformed and made viable. Stimulated by the ever-important central authorities, recent attempts at reconstructing the regional map from a chorographic perspective reflect the need to recognise the supra-municipal scale in a process of municipal belonging that will tend to spread. This development is patent in new readings of Mainland Portugal's regional geography.
\end{abstract}

Key words: Province, region, chorography, reform, NUTS, municipality, belonging.

1 Investigador do Centro de Estudos Geográficos e docente do Departamento de Geografia da Faculdade de Letras da Universidade de Lisboa.

E-mail: sc@ceg.ul.pt 
Résumé - Le Portugal péninsulaire et les défis RÉGIOnaux. Dans un espace sans ruptures physiques marquantes et pourvu d'une notable unité humaine, les délimitations régionales portugaises, nées au Moyen Âge, eurent un caractère principalement chorographique. La désignation des comarcas, devenues ensuite provinces, reflétait davantage le point de vue de ceux qui observaient le pays depuis son centre politique que les identités régionales assumées par les populations. Au XIX ${ }^{\mathrm{e}}$ siècle, les provinces s'effacèrent rapidement au profit des districts, qui regroupèrent alors les municipalités réformées et rendues viables par les Libéraux. Stimulée par un pouvoir central toujours dominant, la tentative récente de reconstruction de la carte régionale est une véritable rénovation chorographique et reflète la nécessité de valoriser une échelle supra-concelho, par un processus d'associativisme municipal en voie de développement, où des lectures nouvelles de la géographie régionale se manifestent. ciativisme.

Mots-clés: Province, région, chorographie, réforme, NUTS, municipalité, asso-

\section{ASSINALÁVEL UNIDADE E UMA CONSTRUÇÃO NACIONAL RÁPIDA}

A divisão regional do continente dificilmente suscita consensos, mas não desperta igualmente grandes polémicas, também entre os geógrafos portugueses, e é ciclicamente trazida para o primeiro plano do debate público. Assumimos, aqui, a região na sua acepção mais vulgar, de divisão infranacional, tendo presente que, etimologicamente, ela é um território dotado de poder próprio, com capacidade de se "reger", e que a regionalização é sempre um processo de descentralização política.

A ambiguidade da construção regional do território peninsular português tem as suas raízes na ausência de regiões de clara delimitação geográfica e na própria evolução histórica do processo regional.

Reconhecendo a ausência de regiões de inequívoca delimitação geográfica, Herman Lautensach (1991) e Orlando Ribeiro (1987a) convergem na inexistência de claras rupturas físicas. O primeiro geógrafo considera que o relevo e o clima não fornecerem critérios claros para aquela divisão e valoriza a «complexidade das condições reais» (Lautensach, 1991: 1233); o segundo, reconhece a dualidade norte-sul, na oposição do Portugal atlântico e transmontano ao meridional (Ribeiro, 1962: 38), mas insiste no entrelaçamento das influências atlânticas e mediterrâneas, cujos contrastes a acção humana ajuda ainda a esbater. A unidade portuguesa resulta igualmente de, ao longo de séculos, diversos povos terem acorrido à Península e contribuído para a formação da sua população; a sua influência fez-se sentir diferentemente, como a presença dos Celtas mais a Norte ou dos Muçulmanos, a Sul, mas, na sequência da Reconquista, estas comunidades integraram-se com relativa facilidade na nação que se constrói, sem definição de grupos étnicos e culturais de base regional. A unidade cultural portuguesa é sublinhada tanto por Jorge Gaspar (1993), que refere a relevância da religião e da língua, como por Carlos Alberto Medeiros (2005: 23), para quem uma assinalável diversidade geográfica do território continental e particularis- 
mos regionais e locais não impedem «a forte identidade cultural» comum. José Mattoso et al. (1997) insiste, por seu turno, na unificação de territórios diversos e com poucas relações entre si, por um poder político firme e centralizador e considera que só lentamente se construiu a Nação portuguesa.

A Reconquista processa-se de uma forma relativamente fácil; quando, em 1249, D. Afonso III derrota as forças muçulmanas no Algarve, o território português vê quase duplicada a sua área de 1143, ano em que se formaliza a independência política. A rapidez da progressão norte-sul portuguesa sobressai na comparação com a conquista liderada por Castela, concluída quase dois séculos e meio mais tarde, e só é possível na ausência de comunidades regionais fortes, capazes de oferecerem uma resistência significativa às forças militares cristãs. O último importante acordo fronteiriço data de 1297 (Tratado de Alcañices) e a estabilidade das fronteiras também reflecte a inexistência de agrupamentos regionais que pudessem fazer oscilar a fronteira; de resto, o carácter fortemente repulsivo das regiões fronteiriças prolonga-se do passado à actualidade (Cavaco, 1995).

\section{PROVÍNCIAS DELIMITADAS A PARTIR DO CENTRO POLÍTICO OU A FÁCIL AFIRMAÇÃO DOS DISTRITOS}

Durante a Reconquista, os monarcas protegem os municípios, que materializam o poder do povo, com quem estabelecem uma relação de cumplicidade, como contra-poder de senhores feudais premiados pelo seu apoio militar. Concluída aquela, os municípios perdem utilidade para os reis que, agora, também tentam limitar a sua autonomia, na centralização política e administrativa em que assenta a construção do Estado. O poder central nomeia quer funcionários, que acompanham directamente a actividade municipal, quer magistrados, cuja actuação se estende por divisões regionais - meirinhos-móres que D. Dinis substitui pelos "corregedores das comarcas". É deste rei que se conhece uma primeira delimitação regional, num codicilo de 1299 (Santos, 1985): a norte do Douro, identifica Entre Douro e Minho, o que significa o carácter periférico do vasto território localizado para o interior e que não é limitado, a norte, pelo Minho. A valorização dos rios na localização está igualmente presente na divisão de Entre Douro e Mondego, que tem a leste a Beira e a sul a Estremadura. No território a sul, D. Dinis identifica o território de Entre Tejo e Odiana, onde inclui o Algarve - recentemente conquistado e a quem é, pois, recusada a diferenciação. O rei alude a Moura e Serpa, na margem esquerda do Guadiana, seguramente pelo receio de perda da soberania portuguesa. Contudo, não estamos a falar de inequívocas regiões: as comarcas não possuíam um aparelho administrativo próprio, nem uma sede, circulando os representantes régios pelas mesmas (Medeiros, 1991: 38).

Nas crónicas dos reis da primeira dinastia, escritas a partir do século XV, encontramos referências regionais dispersas, com uma função de localização e 
não de caracterização territorial (Tarouca, 1952-53); é na Estremadura que ocorre a maioria dos episódios políticos associados à Coroa. As divisões regionais são referidas conjuntamente na crónica do reinado de D. Fernando (Lopes, 1979: 479); habitantes de Lisboa sugerem à rainha regente que tome por conselheiros homens-bons de Entre Tejo e Odiana, Estremadura, comarca da Beira, Trás-os-Montes, Entre Douro e Minho e, por último, Algarve - territórios depois classificados como "comarcas". Este episódio significa que os dirigentes populares da capital interiorizam este mapa regional do país. Na mesma Crónica, refere-se que, anos antes, ao fixar os preços dos cereais (Lopes, 1979: 150), D. Fernando adoptara genericamente a anterior divisão, mas classificara o Algarve de "reino"; apenas a Beira é considerada "comarca" e o Porto é individualizado - já na Idade Média, há dificuldade em inserir a segunda cidade do Reino e a sua área de influência mais directa em Entre Douro e Minho.

Com excepção da designação de Algarve, herdada dos anteriores ocupantes muçulmanos e que significa, para os Muçulmanos, "a ocidente", as identificações de Entre Tejo e Odiana ou Alentejo, Estremadura («na fronteira entre as terras dos cristãos e dos mouros» - Mattoso et al., 1997a: 5-6), Beira (à beira da serra), Entre Douro e Minho e Trás-os-Montes, reflectem tanto a relevância do norte na génese de Portugal como o olhar de quem perspectiva as regiões a partir do centro político português ${ }^{2}$ (fig. 1).

A artificialidade destas divisões também se reconhece nos seus limites pouco precisos, particularmente entre a Beira e a Estremadura (Santos, 1985). De 1530 e 1550, D. João III multiplica o número das comarcas para mais de vinte (quarenta e cinco em 1822), que passam a assumir o carácter de divisão sub-regional das seis, agora, regiões ou províncias (Santos, 1985: 39). Testemunhando o seu enraizamento histórico e corográfico, em 1641, D. João IV recupera-as como circunscrições militares. Com este monarca ascende à Coroa a Casa de Bragança, a única com domínio territorial capaz de afrontar o poder régio e a dinastia que funda aposta na centralização do Estado, com desvalorização dos poderes periféricos, regionais ou locais. Subsiste, contudo, a memória identitária construída no período medieval, como atestam as corografias do século XVIII, em que a informação do Reino surge organizada pelas seis províncias tradicionais ${ }^{3}$.

2 Leite de Vasconcelos (1961) supõe terem sido os minhotos a criar a designação de Trás-os-Montes, como se afigura razoável; contudo, cedo esta assumiu dimensão nacional. O mesmo especialista associa a identificação de Beira ao facto de a província se encontrar junto ao Douro; contudo, esta designação não se aplicou aos territórios na margem norte do rio, e está, em qualquer caso, inequivocamente associada à cordilheira montanhosa que a atravessa, com a divisão em Beira Alta e Beira Baixa. Também Ribeiro (1987a) associa esta designação regional à vizinhança da mesma cordilheira.

3 Assim sucede com a Corografia Portuguesa e Descrição Topográfica do famoso Reino de Portugal, que o Padre António Carvalho da Costa começa a publicar em 1706; a Geografia Histórica de todos os Estados Soberanos de Europa..., de D. Luis Caetano de Lima, de 1734 (de que saem apenas dois volumes), e a Descrição de Portugal, de 1788, de Frei Manuel de Figueiredo (1804). 


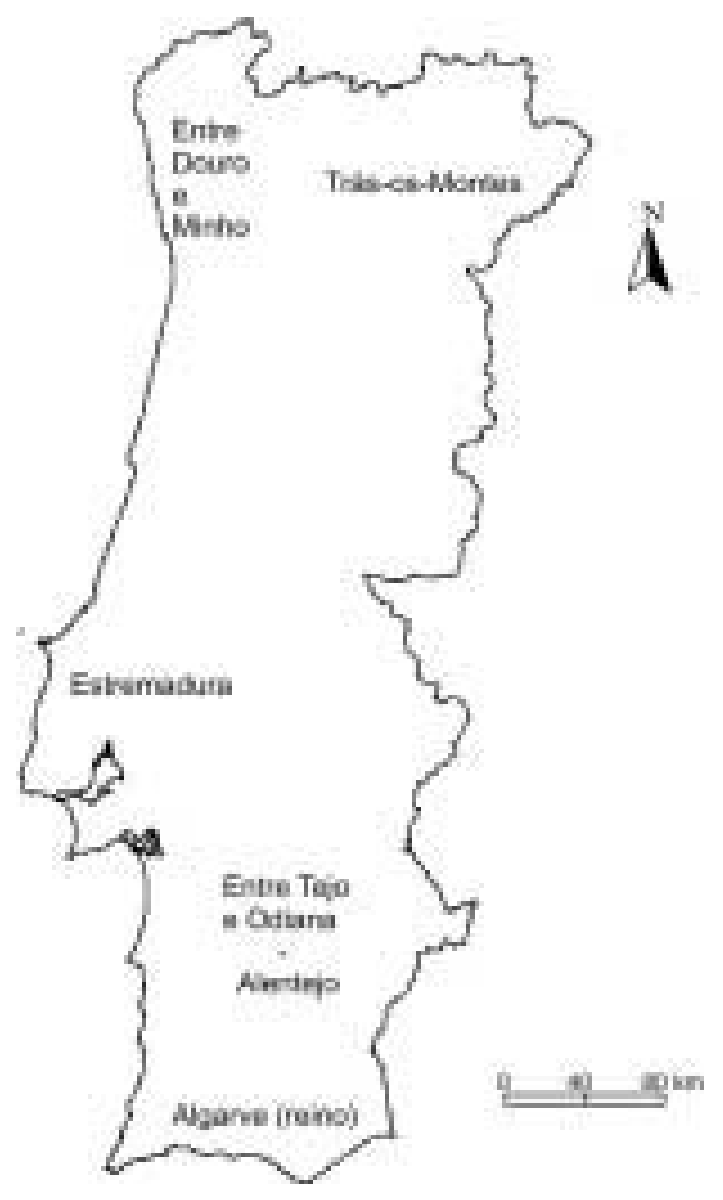

Fig. 1 - As comarcas medievais.

Fig. 1 - Medieval territories.

A reforma militar empreendida com Pombal introduz o efémero "Partido do Porto", repetindo a dificuldade em definir uma região tutelada por esta cidade. Em 1816, nova divisão militar separa a Beira Alta e a Beira Baixa, divididas pela cordilheira central.

No seu revivalismo medieval, os liberais inscrevem na Constituição de 1822 e nos textos que a substituem as seis províncias, com o "Minho" a substituir "Entre Douro e Minho". Na legislação eleitoral de 1827 e de 1828 e político-administrativa deste último ano, retoma-se a divisão provincial tradicional, introduzindo a diferenciação em Beira Alta e Beira Baixa. Em 1833, Mousinho da Silveira divide o Reino em oito províncias, entre elas a do Douro, com sede no sempre problemático Porto. Contudo, os liberais nunca adoptarão as províncias como circunscrições político-administrativas mas, apenas, como referência eleitoral.

Dois anos depois, o Reino é dividido em dezassete distritos administrativos, encimados por um governador e representante do poder central - o que logo é alargado aos Açores e à Madeira. As "ilhas adjacentes" são também divididas em províncias, mas apenas para fins eleitorais. Os distritos administrativos são construídos sobre os municípios, que os liberais românticos apreciam e que, sobretudo para garantir a sua viabilidade económica como autarquias, 
reformam profundamente: em 6 de Novembro de 1836, Passos Manuel reduz o número de concelhos para 351, cerca de metade de um total que se ignora ao certo; no seu esforço de racionalização, outros governos procederão a novas supressões, menos numerosas. A prudência do poder central na criação de novos municípios explica que o seu total atinja hoje, apenas, pouco mais de três centenas.

Os distritos tendem a dividir o território em parcelas semelhantes, particularmente no centro e norte interiores, ignorando ostensivamente as antigas divisões provinciais. Aparte a rápida substituição de Lamego por Viseu como capital (1836), o mapa distrital só é alterado significativamente em 1926, com a nova circunscrição de Setúbal. Os distritos são alvo de críticas sistemáticas, porque marcados pela artificialidade (Martins, s.d.: 41), agrupando concelhos de variadas condições (Girão, 1930: 8) e alheios a tradições territoriais anteriores. Contudo, não deixa de ser significativa a forma como eles se afirmaram, como reconhece Drain (1991: 30):

«(...) il est malaisé d'y distinguer de véritables identités régionales, au point que les circonscriptions administratives de l'ère libérale, en dépit de leur caractère artificiel et de leur création relativement récente, y revêtent désormais une certaine légitimé.»

Para a debilidade das tradicionais divisões provinciais terá concorrido a ausência de cidades de assinalável dimensão que as liderem (Gaspar, 1988), bem como a inequívoca capitalidade de Lisboa. Logo no século XIV, ela é testemunhada por as tropas castelhanas se dirigirem a esta cidade quando pretendem conquistar o país. A sua liderança decorre quer de um processo secular de afirmação da independência frente a Castela/Espanha, quer da edificação e manutenção de um império que fornece à Coroa significativos recursos financeiros. Depois de Setecentos ter tido o seu «século de ouro», no começo do século seguinte, o percurso das tropas napoleónicas e o desenrolar da revolução liberal testemunham, também, o crescente protagonismo do Porto. Contudo, nenhuma das duas principais cidades funciona como importante pólo de migrações internas.

\section{A REGIONALIZAÇÃO CONTRA NATURA DO ESTADO NOVO}

No começo do século XX, Leite de Vasconcelos (1961: 13) remete-se às seis "províncias", que classifica de "divisões populares" - na realidade, ao longo de todo o século XIX, elas continuam a povoar e a organizar os textos escolares de Geografia sobre o território português (Claudino, 2001). Na sequência da instauração de uma República sensível aos desafios da igualdade de oportunidades e da influência do debate sobre justiça territorial que se segue à I Guerra noutros países europeus, em Portugal reacende-se o debate sobre a regionalização do país. Em 1922, realiza-se o Congresso Nacional Municipalista, 
a que se sucedem congressos provinciais e regionais e a criação de associações regionalistas. Para Amorim Girão (1930: 1), proeminente professor de Geografia da Universidade de Coimbra, «O regionalismo é hoje uma ideia em marcha». Assumindo a influência da florescente escola regional francesa e defensor da "região natural", em detrimento da política, elabora uma proposta de divisão em treze regiões, em que valoriza as bacias hidrográficas como unidades geográficas. Apela à mobilização dos recursos naturais de cada região na promoção do seu desenvolvimento, num discurso marcado pela animosidade em relação ao centralismo lisboeta (Amorim Girão, 1930: 2-3):

«Esse movimento... é a consequência lógica duma revolução económica que impõe a especialização da produção... é o país que, farto de apelar em vão para o Estado-providência, reconhece que precisa de fazer uma chamada às próprias forças, procurando valorizar-se pelo aproveitamento de todos os recursos naturais; é Portugal, tomando a consciência de que é mais alguma coisa do que Lisboa, a tentar descongestionar-se por forma que as suas diversas regiões, recuperando a antiga vitalidade, possam opor-se à aglomeração da capital, impedindo que esta continue exercendo a atracção maléfica que tem exercido sobre todas as inteligências, actividades e interesses das populações provinciais.»

Amorim Girão influencia decididamente a divisão em onze províncias aprovada no Código Administrativo de 1936. Contudo, a ditadura do Estado Novo faz o seu curso centralista: as juntas de província são esvaziadas de competências e recursos e as províncias são extintas em 1959, ainda que com a cuidadosa advertência de que «Sem prejuízo da designação regional "província" ${ }^{4}$. No ano anterior, Amorim Girão (1958) povoara o continente de estereótipos regionais, como as seareiras alentejanas, o pastor beirão ou o pescador minhoto; antes, Orlando Ribeiro (1957) reconhecera que as províncias constituem, sobretudo, unidades de identificação "sentimental" dos portugueses, mas observava que os distritos, apesar de divisões heterogéneas, adquiriram alguma tradição.

Entretanto, o sistema de ensino continua a divulgar até aos nossos dias a divisão provincial de 1936 (Claudino, 2001), marcando sucessivas gerações. Contudo, os acontecimentos que marcam a evolução da população de Portugal peninsular apontam para uma diluição das identidades regionais. A partir dos anos 60 do século passado, o país sofre uma autêntica sangria interna, através da emigração, ao mesmo tempo que se acentua o êxodo rural para as principais cidades do litoral, movimentos que penalizam particularmente as áreas rurais. Após 1974, regressam centenas de milhares de "retornados" das ex-colónias, que se pulverizam por todo o país e, com o seu assinalável dinamismo, marcam decididamente o desenvolvimento regional e local. Desde os anos 90, a imigração de cidadãos leste-europeus, brasileiros, dos países africanos lusófonos e outros, assumiu igualmente uma assinalável expressão por todo o Continente, 
tendo quase duplicado os estrangeiros recenseados entre 1991 e 2001. Simultaneamente, subsistem as migrações internas em direcção ao litoral. Jorge Malheiros (2006: 122) assinala que, apenas entre 1995 e 2001, mudaram de município de residência $6,6 \%$ da população total, o que também nos dá uma noção da intensidade destas migrações. A mobilidade da população portuguesa e o acolhimento de numerosos imigrantes contribuem, seguramente, para a referida diluição das identidades regionais.

\section{REGIONALIZAÇÃO PROTELADA E FORTE DINAMISMO MUNICIPAL}

Na sequência do III Plano de Fomento (1968/1973) e das preocupações aí manifestadas quanto à preponderância de Lisboa e Porto e tendo por base o mapa dos distritos, Portugal peninsular é dividido, em 1969, nas regiões Norte, Centro, Lisboa e Sul, cada uma delas encimada por uma Comissão de Planeamento Regional - lançam-se, assim, os fundamentos das divisões hoje comummente aceites.

A revolução democrática de 1974 recupera as aspirações de promoção dos territórios menos desenvolvidos. Dois anos depois, a Constituição institui as regiões administrativas, autarquias locais que devem corresponder às regiões-plano, subsistindo os distritos apenas enquanto não estiverem instituídas as regiões. Com uma individualidade geográfica inequívoca, os arquipélagos dos Açores e da Madeira adquirem o estatuto de Regiões Autónomas, com órgãos de soberania próprios (governo e parlamento regionais) e iniciam um processo autonómico de assinalável dinamismo, distinto daquele que se desenrola no Continente.

Entretanto, o poder autárquico municipal ganha novo dinamismo. Em 1979, são criados os Gabinetes de Apoio Técnico ${ }^{5}$ e, cinco anos depois, o governo autoriza a criação de Associações de Municípios ${ }^{6}$, que cooperam tanto na gestão dos recursos técnicos como na resolução de problemas que se colocam à escala supramunicipal (ambiente, transportes, turismo, etc.). O governo sanciona e estimula uma situação de facto: em 1983, constituíra-se já a Associação de Municípios do Distrito de Setúbal, a primeira do país. Esta integra a totalidade dos municípios do contrastado distrito de Setúbal, o que reflecte a força das relações construídas sob a identificação distrital; também a Sul, encontramos duas outras associações fortemente identificadas com os distritos: a Associação de Municípios do Distrito de Évora (sem Reguengos de Monsaraz) e a Associação de Municípios do Algarve, que compreende todos os municípios do distrito de Faro.

5 Decreto-Lei n. ${ }^{o}$ 58/79, de 29 de Março.

6 Decreto-Lei n. ${ }^{\circ}$ 99/84, de 29 de Março. 
Ainda em 1979, as Comissões de Planeamento Regional são substituídas pelas Comissões de Coordenação Regional (CCR) ${ }^{7}$, agora em número de cinco, com a divisão do Sul em Alentejo e num Algarve cujo dinamismo socioeconómico se acentua; a parte meridional do distrito de Setúbal passa a integrar a CCR do Alentejo. Já em 1991, são criadas as Áreas Metropolitanas de Lisboa e do Porto $^{8}$, pelo agrupamento dos municípios respectivos.

Em 1980, o governo publica o Livro Branco sobre Regionalização e, antes e depois dessa data, desenvolvem-se projectos de divisão regional, elaborados tanto por organismos oficiais como por partidos políticos, em que as principais diferenças residem na integração ou diferenciação dos territórios do litoral e do interior. Contudo, está cada vez mais distante o idealismo regionalista da revolução de 1974 e da crise económica subsequente. Os anos que se seguem à adesão comunitária são de acentuado crescimento económico nacional, com desvalorização do apelo à promoção dos recursos endógenos das áreas mais rurais e periféricas; Lisboa vê reforçada a sua centralidade: as privatizações das grandes empresas levam à reconstrução dos principais grupos económicos, geralmente sediadas na capital; as importantes ajudas financeiras da União Europeia são redistribuídas a partir de Lisboa e, por último, na valorização da escala europeia (Vandermotten et al., 1999), surge como decisivo para Portugal a projecção das suas duas maiores cidades - esforço que explica, em grande medida, a Exposição Mundial de Lisboa, de 1998. A regionalização prevista na Constituição vai sendo protelada; apenas em 1991 é aprovada a Lei-Quadro das regiões administrativas ${ }^{9}$. Só sete anos depois, a Assembleia da República institui regiões administrativas em Portugal peninsular ${ }^{10}$ : Entre Douro e Minho; Trás-os-Montes e Alto Douro; Beira Litoral; Beira Interior; Estremadura e Ribatejo; Lisboa e Setúbal; Alentejo e Algarve. O esforço de recuperação do mapa corográfico tradicional é evidente, em detrimento das cinco regiões-plano em vigor; no norte e centro, divide-se o litoral e o interior, na valorização das suas assimetrias. A área metropolitana de Lisboa é consagrada, sob a designação dos seus dois principais pólos urbanos, Lisboa e a mais distante Setúbal; nela incluem-se os municípios mais rurais do norte do distrito de Lisboa, a significar, uma vez mais, a subsistência do vínculo distrital. Na designação da região de Estremadura e Ribatejo esquece-se que os territórios de Lisboa e Setúbal integram tradicionalmente a Estremadura. É difícil dividir o Centro, onde Coimbra carece de uma inequívoca liderança perante Leiria, Aveiro, Viseu, Castelo Branco ou, mesmo, Guarda, cidades agora repartidas por três regiões administrativas diferentes. A área metropolitana do Porto não se individualiza - o que tanto permite a leitura de um menor dinamismo regional, como o esforço em liderar todo

\footnotetext{
Decreto-Lei n. ${ }^{\circ} 494 / 79$, de 21 de Dezembro.

Lei n. ${ }^{\circ}$ 44/91, de 2 de Agosto.

9 Lei n. ${ }^{\circ}$ 56/91, de 13 de Agosto.

10 Lei n. ${ }^{\circ} 19 / 98$, de 28 de Abril.
} 
o Norte. Quando ainda ecoam os ecos do sucesso nacional da EXPO, solicitados a pronunciarem-se sobre a instituição das regiões administrativas e daquela da sua área de recenseamento eleitoral, a maioria dos portugueses alheia-se desta votação (participam 48,29\% dos eleitores) e os que nela participam recusam tanto a regionalização administrativa $(60,84 \%)$ como a instituição da sua região da sua área de recenseamento $(58,92 \%)^{11}$.

A recusa da regionalização surge ao arrepio do projecto político da União Europeia. Com uma política regional instituída apenas a partir de meados dos anos 70, a integração territorial pretendida pelos seus responsáveis compagina-se menos com uma Europa de países, herdeiros directos de estados-nação ciosos das suas identidades e interesses, e mais com o de uma Europa das Regiões, com as quais as autoridades comunitárias desenvolvem um diálogo mais fácil e de alguma cumplicidade frente aos governos nacionais. Em nome de uma coesão territorial que exige a aposta nas regiões mais desfavorecidas, como se lê na mal sucedida Constituição Europeia ${ }^{12}$, os fundos estruturais mais importantes têm matriz regional, como sucede com o Fundo Europeu de Desenvolvimento Regional (FEDER) e o Fundo Europeu de Orientação e de Garantia Agrícola (FEOGA). A própria Comissão Europeia lamentou publicamente o resultado negativo do referendo português sobre a regionalização.

\section{O ENSAIO DE NOVAS CONFIGURAÇÕES REGIONAIS}

Em 1986, tendo em vista a uniformização da recolha de informação estatística no âmbito da União Europeia, instituem-se em Portugal as unidades territoriais para fins estatísticos - NUTS ${ }^{13}$, definidas em $1989^{14}$, tendo presente o mapa das regiões e zonas agrárias. Num primeiro nível, surgem o Continente, a Região Autónoma dos Açores e a Região Autónoma da Madeira. $\mathrm{Na}$ desagregação de nível II, e para além das Regiões Autónomas, presentes nos três níveis de NUTS, encontramos os territórios de actuação das Comissões de Coordenação Regional: Norte, Centro, Lisboa e Vale do Tejo, Alentejo e Algarve.

Uma vez mais, as NUTS III constroem-se por agrupamento dos municípios (fig. 2). Apesar das finalidades estatísticas que presidiram à sua criação, elas acabam por esboçar novas configurações regionais ou consolidar outras. Consagram-se as principais áreas urbanas do litoral: Grande Lisboa, Grande Porto e Península de Setúbal. Outras designações, recuperam, total ou parcialmente, as designações provinciais, maioritariamente no interior e sul, áreas mais

\footnotetext{
11 Fonte: http://www.stape.pt/

12 Artigo III-220. ${ }^{\circ}$.

13 Resolução do Conselho de Ministros n. ${ }^{\circ}$ 34/86, de 26 de Março.

14 Decreto-Lei n. ${ }^{\circ}$ 46/89, de 15 de Fevereiro.
} 
periféricas e onde estas designações subsistirão com mais força: Alto Trás-os-Montes, Beira Interior Norte, Beira Interior Sul, Alto Alentejo, Alentejo Central, Alentejo Litoral, Baixo Alentejo e Algarve. No litoral, a norte de Lisboa, de assinalável dinamismo socioeconómico, e no centro-interior, onde os limites provinciais são menos claros, encontramos a maioria das novas designações. Estas recuperam traços geográficos, em particular as sempre pacíficas designações de rios. Neste caso, encontram-se Minho-Lima, Cávado, Ave, Tâmega, Douro, Entre Douro e Vouga, Dão-Lafões, Baixo Vouga, Baixo Mondego, Médio Tejo e Lezíria do Tejo. Valorizando outros aspectos geográficos, surgem as identificações de Serra da Estrela, Cova da Beira, Pinhal Interior Norte, Pinhal Interior Sul, Pinhal Litoral e Oeste. Neste último caso, por exemplo, confirma-se uma identificação regional nascente: em 1987, surgira a Associação de Municípios do Oeste, cuja constituição se sobrepõe, em grande medida, à da NUTS III.

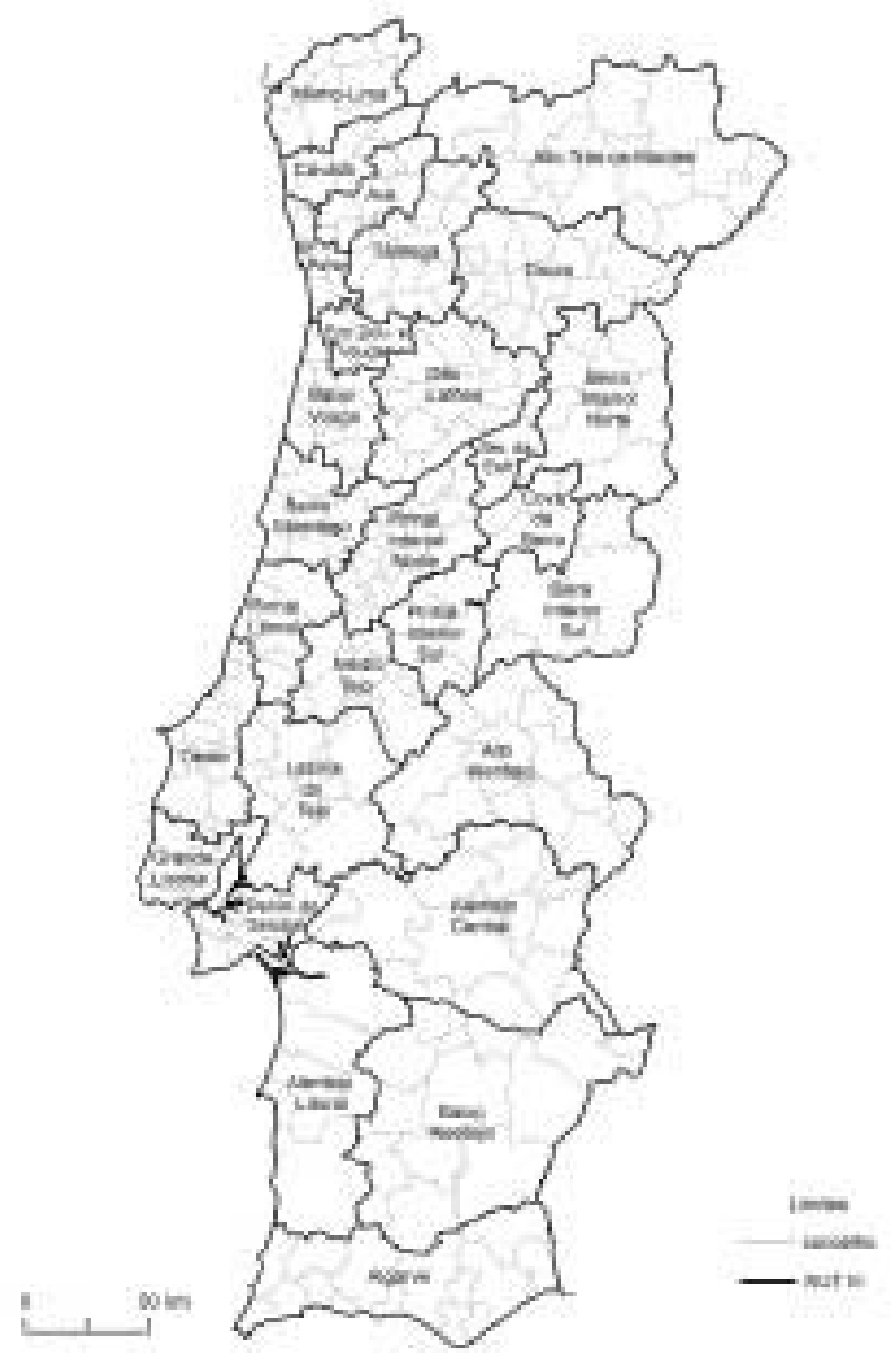

Fig. 2 - Nomenclatura das Unidades Territoriais para fins estatísticos/NUTS de nível III no Continente.

Fig. 2 - Nomenclature of Territorial Units for Statistics/Level III NUTS for Mainland Portugal. 
Para além de designar os municípios que as integram, a legislação que institui as NUTS indica o total daqueles, as respectivas áreas e a população. Com base nestes critérios, percebem-se mal algumas delimitações, como, por exemplo, a Serra da Estrela, com apenas três municípios e uma população muito inferior à de outras NUTS - a dificultar a própria comparação estatística.

Em 2002, perante a expectativa de Lisboa e Vale do Tejo deixar de aceder aos fundos comunitários previstos para o Objectivo 1, no âmbito da Política Regional Comunitária, o governo invoca a defesa dos «interesses nacionais nas negociações» do IV Quadro Comunitário de Apoio e a das «regiões mais atrasadas» daquela NUTS $\mathrm{II}^{15}$ e determina que o Oeste e o Médio Tejo sejam integrados, respectivamente, no Centro e no Alentejo ${ }^{16}$. A anterior NUTS II passa a compreender a Grande Lisboa e a Península de Lisboa, e a designar-se, apenas, de Lisboa. No ano seguinte, o Oeste e o Médio Tejo passam a incluir a área de intervenção da, agora, Comissão de Coordenação e Desenvolvimento Regional (CCDR) do Centro e a Lezíria do Tejo fica sob a alçada da CCDR do Alentejo. Dificilmente se poderia ir mais longe na sobreposição entre NUTS II e divisões político-administrativas ${ }^{17}$. O presidente da CCDR é nomeado pelo governo, integrando os presidentes das câmaras municipais da sua área de intervenção o respectivo Conselho Regional. Este processo de reajustamento regional decorreu sem uma contestação significativa, tanto por parte dos municípios como das associações de municípios envolvidos.

Também em 2003, o governo inicia um processo alternativo ao da regionalização recusada em referendo. Cria as "áreas metropolitanas", subdivididas em "grandes áreas metropolitanas", com um mínimo de nove municípios e 350.000 habitantes, e "comunidades urbanas" com, pelo menos, três municípios e 150.000 habitantes ${ }^{18}$. Dificilmente se percebem designações que classificam de "urbanos" os municípios portugueses, independentemente das suas características. Esta perplexidade estende-se às "áreas metropolitanas": qualquer associação de municípios que ultrapasse os mínimos indicados, mesmo se aqueles são dominantemente rurais, pode assumir-se como tal - como se chegou a especular em relação ao Alentejo. Os municípios podem-se agrupar, ainda, em "comunidades intermunicipais", de menores atribuições e para as quais não são definidos limiares mínimos ${ }^{19}$.

Através dos respectivos órgãos autárquicos, os municípios decidem a sua associação, respeitado o princípio da continuidade territorial, num processo mais próximo do associativismo municipal do que da regionalização. De resto, a defi-

15 Gabinete do Ministro das Cidades, Ordenamento do Território e Ambiente - Nota Justificativa da proposta de Decreto-Lei. 3 (documento policopiado).

16 Decreto-Lei n. ${ }^{\circ}$ 244/2002, de 5 de Novembro.

17 N. 5 do Artigo 4. ${ }^{\circ}$ do Decreto-Lei n. ${ }^{\circ}$ 97/2003, de 7 de Maio, e n. ${ }^{\circ} 1$ do Artigo $2 .^{\circ}$ do Decreto-Lei n. ${ }^{\circ} 104 / 2003$, de 23 de Maio.

18 Lei ${ }^{\circ} 10 / 2003$, de 13 de Maio.

19 Lei ${ }^{\circ} 11 / 2003$, de 13 de Maio. 
nição das competências e recursos destas novas construções regionais fica parcialmente dependente de acordos com o poder central. A constituição das Grandes Áreas Metropolitanas e das Comunidades Urbanas, bem como das Comunidades Intermunicipais ${ }^{20}$, decorre sem fortes polémicas. Com frequência, reajustam-se as anteriores associações de municípios e áreas metropolitanas; contudo, numerosos municípios, sobretudo da Beira Baixa e do Alentejo, não chegaram a definir a sua associação. Em 2005, as mudanças governamentais deixam em suspenso a evolução do processo desencadeado dois anos antes.

No novo mapa regional (fig. 3), surgem apenas duas Comunidades Intermunicipais, confirmando-se, assim, o seu carácter residual de agrupamentos ditados, sobretudo, pela incapacidade em construir uma das outras modalidades de associação. As Comunidades Urbanas recuperam as referências regionais, com a Comunidade Vale-e-Mar, sediada em Viana Castelo, a constituir a principal novidade; institui-se a Área Metropolitana de Leiria, Comunidade Urbana apenas por não se ter conseguido a adesão de municípios que permitissem atingir os totais exigidos legalmente para uma Grande Área Metropolitana. Nestas Grandes Áreas, a do Algarve tem a esperada identificação regional e Braga encabeça a Grande Área Metropolitana do Minho, em evidente esforço de afirmação como capital regional. Para além de Lisboa e Porto, Aveiro, Viseu e Coimbra lideram outras tantas Grandes Áreas Metropolitanas. As principais cidades da faixa litoral (com excepção de Viseu) assumem-se como pólos regionais, em clara ruptura com as tradições corográficas.

\section{O APROFUNDAMENTO DE PERCURSOS REGIONAIS DE BASE MUNICIPAL}

A evolução regional portuguesa demonstra a fragilidade das divisões que se vão desenhando sobre o Continente. Sentir-se beirão, alentejano ou minhoto (mas ninguém se assumirá como "estremenho") não tem obstado a que o poder central desenhe e redesenhe outras configurações regionais, pelo agrupamento, ou não, de distritos, mas sempre pela junção de concelhos. Na realidade, estes surgem como o elemento de identificação territorial mais forte e o único que, na actualidade, parece capaz de suscitar situações de confronto significativas; mesmo nas áreas rurais, as freguesias têm um menor significado autárquico e identitário. Entretanto, os próprios municípios, com um dinamismo consensualmente reconhecido, aderem rapidamente às propostas de associação intermunicipal veiculadas pelo poder central.

Recentemente, assiste-se a uma singular recuperação da referência à "região" nas principais áreas urbanas, por protagonistas das novas formas de consumo, como grandes superfícies comerciais ou a nova imprensa de distribuição gratuita

20 Apenas se constituíram duas, a do Vale do Minho e a do Pinhal. 


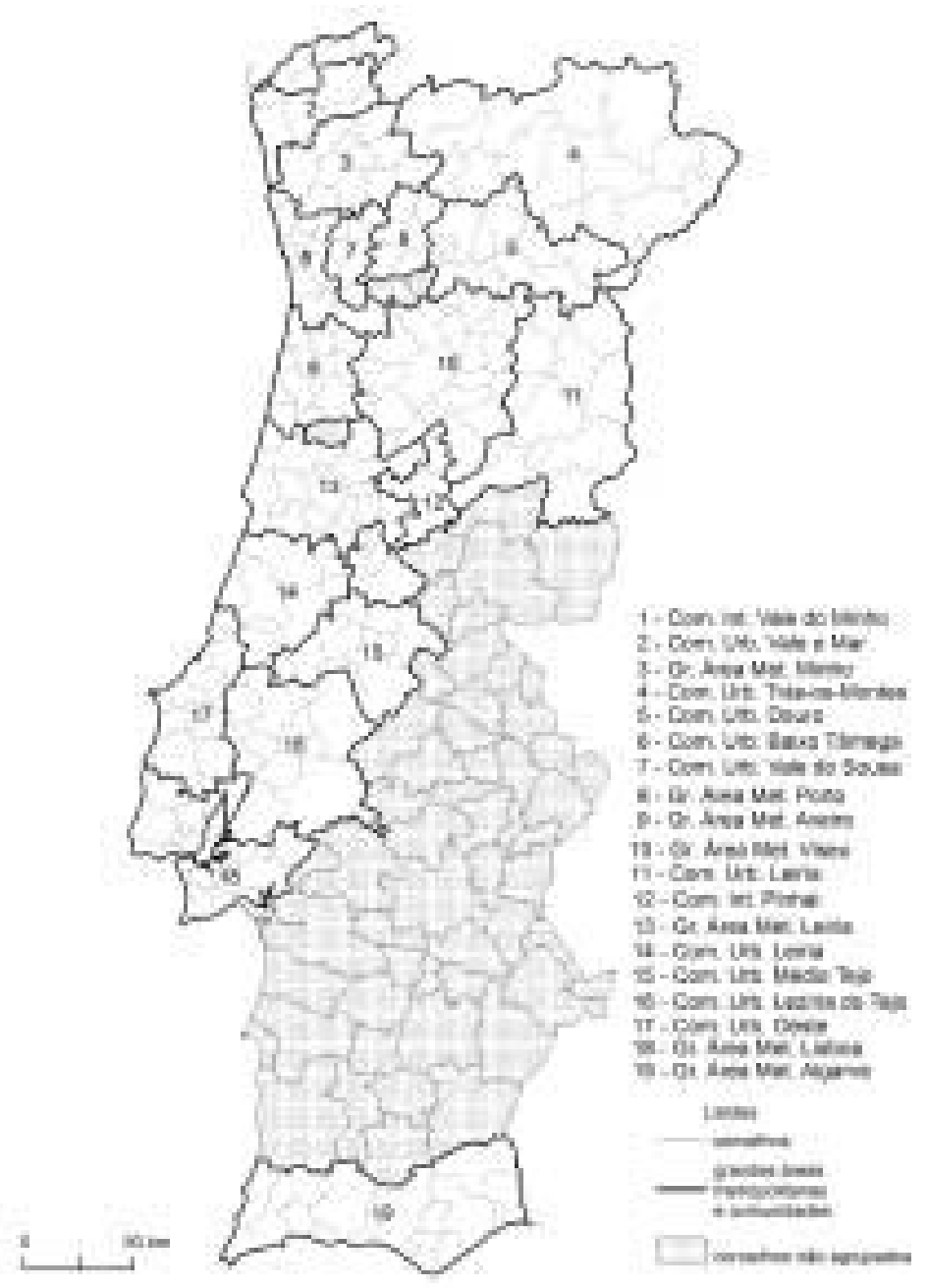

Fig. 3 - Áreas Metropolitanas e Comunidades Intermunicipais.

Fig. 3 - Metropolitan areas and intermunicipal communities.

e maciça; contrariando o estilhaçamento de referências culturais, designadamente locais, pretende-se, aparentemente, recuperar um conceito simpaticamente associado a reminescências identitárias rurais. Mas, para lá desta episódica função identitária, justifica-se a (re)valorização da escala regional? O Continente é crescentemente marcado por contrastes de desenvolvimento e os desafios que se colocam às populações de um interior despovoado são distintos dos que surgem nas áreas cada vez mais urbanizadas do litoral. A escala supra-municipal surge como imprescindível na definição de políticas sociais e económicas que não se esgotam na cooperação entre municípios e compreendem, necessariamente, a definição de novas competências e meios de intervenção, com a consequente criação de úteis elites que protagonizem políticas de âmbito regional.

As perspectivas desenvolvidas, desde o final dos anos 80, tanto por uma "nova geografia regional", que recupera o significado das características físicas do território e das tradições culturais mas encara as regiões, sobretudo, como construções sociais dinâmicas e em forte interacção com escalas mais globais (Albet I Mas, 1993; Malheiros, 2002), como por uma geografia social, que afirma o primado dos factos sociais sobres os espaciais (Benito Del Pozo, 2004), 
fornecem-nos instrumentos para a problematização da evolução regional de Portugal peninsular. Pela sua homogeneidade e tradição, bem como pela própria necessidade de uma significativa afirmação internacional, dificilmente será subalternizado o poder central. Estimulado por este e pela própria União Europeia e liderada pelos municípios com os principais centros urbanos, acreditamos que se assistirá ao aprofundamento da construção de quadros regionais ancorados no agrupamento de municípios, com finalidades flexíveis e em resposta aos desafios colocados em cada período. Aprofundando e/ou reformulando os percursos identitários e de desenvolvimento percorridos desde os anos 80 .

\section{BIBLIOGRAFIA}

Albet I Mas A (1993) La Nueva Geografia regional o la construcción social de la région. Anales de Geografia de la Universidad Complutense, 13, Madrid: 11-29.

Benito Del Pozo P (2004) Planteamientos críticos y alternativos en Geografía. Finisterra - Revista Portuguesa de Geografia, XXXIX (78), Lisboa: 47-62.

Cavaco C (1995) Um olhar sobre a fronteira Portugal-Espanha. In Cavaco C (coord.) As regiões de fronteira: inovação e desenvolvimento na perspectiva do mercado único europeu. Centro de Estudos Geográficos, Universidade de Lisboa, Lisboa.

Claudino S (2001) Portugal através dos manuais escolares de Geografia. Século XIX. As imagens intencionais. Universidade de Lisboa, Lisboa (pol.).

Claudino S (2003) Educação geográfica, divisões administrativas e cidadania local: o desafio incontornável. Apogeo - Revista da Associação de Professores de Geografia, 25: 34-42.

Drain M (1991) Les identités régionales de la Péninsule Ibérique. In Centre d'Études Nord du Portugal - Aquitaine (CENPA) - L'Identité Régionale: L'idée de région dans l'Europe du Sud-Ouest, Actes des Deuxièmes Journées d'Études Nord du Portugal-Aquitaine. Éditions du Centre Nationale de la Recherche Scientifique, Paris.

Gaspar J (1988) Réseau urbain et régionalisation. Annales de Géographie, 341: 291-307.

Gaspar J (1993) As regiões portuguesas. Direcção-Geral do Desenvolvimento Regional, Lisboa.

Girão A A (1930) Esboço duma carta regional de portugal: com a indicação das bases para a classificação das sub-regiões portuguesas. Coimbra Editora, Coimbra.

Girão A A (1958) Atlas de Portugal. Instituto de Estudos Geográficos, Coimbra.

Lautensach H (1991) A divisão regional. In Ribeiro O, Lautensach H, Daveau S (eds) Geografia de Portugal: A vida económica e social. Edições João Sá da Costa, Lisboa: 1231-1239.

Lopes F (1979) Crónica do Senhor Rei Dom Fernando Nono Rei Destes Regnos. Livraria Civilização Editora, Porto.

Malheiros J M (2002) Revisitar a Ilha do Corvo: diálogos entre a Geografia Regional Clássica e a(s) Nova(s) Geografia(s) Regional(ais). In Cachinho H et al. (ed.) Olhares sobre o Território e a Espacialidade. Centro de Estudos Geográficos, Universidade de Lisboa, Lisboa: 127-151.

Malheiros J (2006) Migrações. In Medeiros C A (dir.) Geografia de Portugal, vol. 2: Sociedades, Paisagens e Cidades. Círculo de Leitores, Rio de Mouro: 87-125.

Martins O (s. d.) História de Portugal. vol. I. Publicações Europa-América, Mem Martins. 
Mattoso J et al. (1997a) Portugal - O sabor da terra. Círculo de Leitores/Pavilhão de Portugal/Expo'98, Lisboa.

Mattoso J et al. (1997b) Portugal - O sabor da terra. Estremadura. Círculo de Leitores/ Pavilhão de Portugal/Expo'98, Lisboa.

Medeiros C A (1991) Quelques réflexions à propos des identités régionales au Portugal. L'identité régionale. L'idée de Région dans l'Europe du Sud-Ouest. In Centre d'Études Nord du Portugal - Aquitaine (CENPA) - L'Identité Régionale: L'idée de région dans l'Europe du Sud-Ouest, Actes des Deuxièmes Journées d'Études Nord du Portugal-Aquitaine. Éditions du Centre Nationale de la Recherche Scientifique, Paris.

Medeiros C A (2005) Um preâmbulo geral. In Medeiros C A (dir.) Geografia de Portugal, vol. 1 O Ambiente Físico. Círculo de Leitores, Rio de Mouro.

Ribeiro O (1957) A Geografia e a divisão regional do país, problemas da administração local (separata). Biblioteca do Centro de Estudos Sociais, Lisboa.

Ribeiro O (1962) Aspectos e problemas da expansão portuguesa. Junta de Investigações do Ultramar, Lisboa.

Ribeiro O (1987a) A formação de Portugal. Instituto de Cultura e Língua Portuguesa, Lisboa.

Ribeiro O (1987b) Portugal, o Mediterrâneo e o Atlântico (5. edição). Livraria Sá da Costa Editora, Lisboa.

Santos J A (1985) Regionalização, processo histórico. Livros Horizonte, Lisboa.

Tarouca C S (1952-53) Crónicas dos sete primeiros reis de Portugal (3 vols). Academia Portuguesa de Histórica, Lisboa.

Vandermotten C, Vermoesen F, De Lannoy W, De Corte S (1999) Villes d'Europe, cartographie comparative. Bulletin du Crédit Communal, 53e (207-208), Bruxelles.

Vasconcelos J L (1961) Estudos de filologia portuguesa. Livros de Portugal, Rio de Janeiro. 